\title{
An UHF RFID Reader Antenna with Multitag Identification for Extremely Low-Temperature Medical Systems
}

\author{
Ji S. Jung $\mathbb{D}^{1}{ }^{1}$ Jung N. Lee, ${ }^{2}$ Joung M. Kim $\mathbb{D}^{1},{ }^{1}$ and Jong K. Park $\mathbb{D}^{3}$ \\ ${ }^{1}$ Technology Commercialization Division, Electronics and Telecommunications Research Institute, Daejeon 34129, \\ Republic of Korea \\ ${ }^{2}$ Communications \& Media Research Laboratory, Electronics and Telecommunications Research Institute, Daejeon 34129, \\ Republic of Korea \\ ${ }^{3}$ Department of Mobile Convergence Engineering, Hanbat National University, Daejeon 34158, Republic of Korea
}

Correspondence should be addressed to Jong K. Park; ingpark@hanbat.ac.kr

Received 28 February 2020; Revised 17 May 2020; Accepted 13 June 2020; Published 10 July 2020

Academic Editor: María Elena de Cos Gómez

Copyright $\odot 2020$ Ji S. Jung et al. This is an open access article distributed under the Creative Commons Attribution License, which permits unrestricted use, distribution, and reproduction in any medium, provided the original work is properly cited.

A radio frequency identification reader antenna having multitag identification for medical systems is presented, which consists of four PIFAs, two hybrid couplers, and four power dividers. The high isolation is achieved by the symmetric design of the antenna geometry and four power dividers, which are fed by two hybrid couplers. The experimental results show an isolation of more than $40 \mathrm{~dB}$ in the North American (902-928 MHz), Korean (917-923.5 MHz), and Japanese (916.7-923.5 MHz) RFID frequency bands.

\section{Introduction}

The low-frequency (LF) and the high-frequency (HF) RFID systems make use of inductive coupling to carry power and data transmission between the tag and the reader antenna [1]. The UHF and microwave RFID systems use the propagation of electromagnetic (EM) waves to transfer information between the tag and reader antenna. LF and HF RFID systems are used for near-field RFID systems to use their security merits. However, the large size of the antenna limits its application in small items. Because the frequency band is low, the data transmission rate is slow and the transmission data volume is limitary. The UHF near-field RFID system is receiving much attention because of its promising item-level applications in pharmaceutical and medical systems. The physical antenna size can be suitably reduced to accomplish item-level tagging for small items, which requires the attachment of small antennas. The receiving reliability of the RFID reader antenna has been enhanced by the development of an HF band mutual coupling and UHF band backscattering method that combines a UHF band near-field RFID reader antenna such as a near field of microstrip antennas [2], the near field of a wire grid model [3], UHF near-field RFID reader antenna with capacitive couplers [4], an electrically large zero-phase-shift line grid array UHF near-field RFID reader antenna [5], a planar near-field RFID reader antenna for item-level tagging [6], and a novel broadband center-fed UHF near-field RFID reader antenna [7]. Typical UHF band near-field reader antenna forms a strong perpendicular magnetic field in the aperture and provides good identification of the tag for the near field. However, it has the defect of being unable to identify the tag in the far-field region. This increases the need for a single hybrid reader antenna that can identify near-and far-field tags at the same time. The tag antennas are powered by a continuous wave RF signal transmitted by a reader, and backscattering transmission from the reader sends back their data. The RF receiver of the reader inputs not only reflected signal from the tag but also leaked waves sent from the RF transmitter. This leakage wave makes a dent in the receiving sensitivity of the reader. The directly coupled continuous wave signal is much larger than the backscattered wave from tags, and the receiving part of the reader should detect the weak signal close to such a strong operating band interferer. The research on methods for improving the isolation to minimize this leakage signal is progressing [8-14]. 
Circularly polarized $(\mathrm{CP})$ reader antennas are widely used for UHF RFID systems [15-23]. In order to obtain wellread performance, the reader antennas need to be designed for $\mathrm{CP}$, because $\mathrm{CP}$ antennas can increase orientation diversity and reduce the loss caused by the multipath effects between the reader and the tag antenna. The feeding structures of $\mathrm{CP}$ antennas can be categorized into single and multifeed. Single-feed CP antennas [15-20] have the advantages of simple structure, easy manufacture, and small size. However, the single-feed CP antenna, in its simplest form, has inherently narrow $\mathrm{AR}$ and narrow impedance bandwidths.

The multifeed CP antennas have wider bandwidths than single-feed structures. The multifeed CP antennas use a hybrid feed network [21-23] and Wilkinson power dividers. This achieves wide impedance bandwidths and AR bandwidths. However, the multifeed $\mathrm{CP}$ antennas have low radiation efficiency and large size. Most of these antennas either have large antenna heights or narrow impedance bandwidths, which may not be suitable for practical applications.

In this paper, we present a design for a UHF RFID reader antenna having multitag identification for medical systems. We improved the isolation between the antennas by using two hybrid couplers and four power dividers. The proposed reader antenna covers a range of North American (902-928 MHz), Korean (917-923.5 MHz), and Japanese (916.7-923.5 MHz) RFID frequency bands and its $\mathrm{Tx} / \mathrm{Rx}$ isolation is $40 \mathrm{~dB}$. The multitag identification rate is compared using a far-field reader antenna (Alien reader antenna) and a near-field reader antenna (MTG reader antenna). The simulation and fine-tuning of the reader antenna were carried out by using the commercial software Ansys HFSS. The proposed antenna has excellent isolation characteristics and a multitag identification rate.

\section{Design of the Planar Inverted F Antenna}

The geometry and dimensions of the configuration are depicted in Figure 1. It has the dimensions of $150 \mathrm{~mm} \times$ $150 \mathrm{~mm}$, and the dielectric substrate of FR-4 (thickness: $1.0 \mathrm{~mm}, \varepsilon r=4.4$, loss $\delta=0.025$ ) is used.

The prototype consists of three $0.035 \mathrm{~mm}$ thickness copper layers with the one antenna and upper ground plane placed at the top and a bottom ground plane placed at the bottom. The antenna is probe fed and a shorting line connects the upper ground plane.

Figure 2 shows the measured and simulated reflection coefficient of the Planar Inverted F Antenna (PIFA). The simulation results are obtained using the simulation tool Ansys HFSS [24], and the reliability of the obtained results is confirmed. The measured frequency ranges from 860 to $960 \mathrm{MHz}$ in the UHF band and has a $100 \mathrm{MHz}$ bandwidth, which agrees well with the HFSS simulated results. We investigated the effects of the geometrical parameters on the reflection coefficient by measuring the reflection coefficients for the different parameters.

Figure 3 shows the measured reflection coefficient for different radiator lengths and separation distances between the shorting and feed lines. Figure 3(a) shows that as the

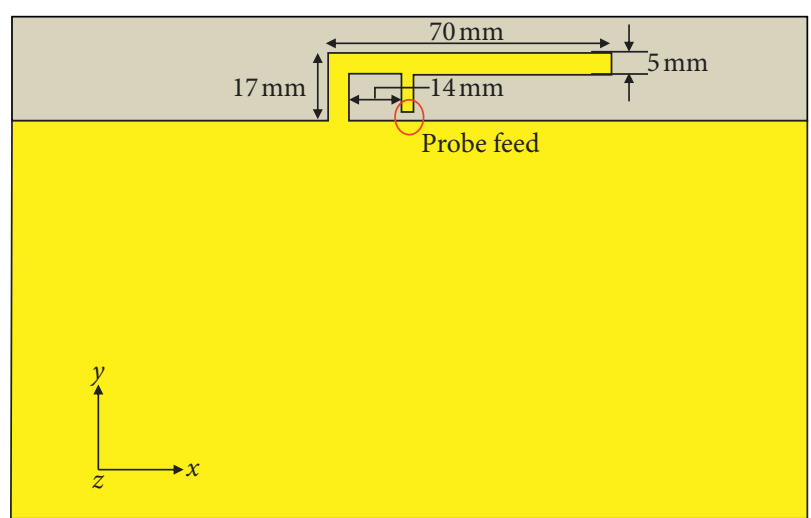

Figure 1: Geometry of the proposed PIFA.

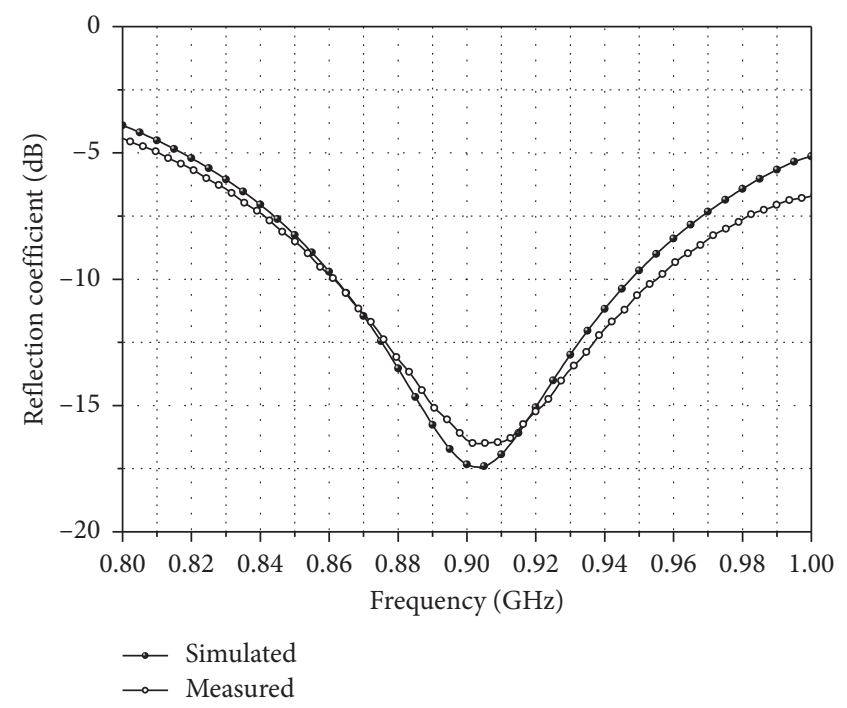

FIGURE 2: Measured and simulated results of the PIFA.

radiator length $(L)$ is increased, the UHF RFID frequency band is moved to the lower frequency. The optimized value in this design is $70 \mathrm{~mm}$. The whole antenna structure cannot be changed, and the frequency can be controlled rather simply. As shown in Figure 3(b), as the distances $(D)$ between the shorting and feed lines increases, the antenna impedance becomes poor. The optimized value in this design is $14 \mathrm{~mm}$.

The measured and simulated radiation patterns at 860 , 920 , and $960 \mathrm{MHz}$ for the proposed antenna are plotted in Figure 4 . The radiation patterns in the $x z$-plane are nearly omnidirectional for all frequencies, and those in the $y z$-plane are very monopole-like. These radiation patterns are also stable across the respective operating frequency bands. The measured antenna gains are $2.7 \mathrm{dBi}$ at $860 \mathrm{MHz}, 2.9 \mathrm{dBi}$ at $920 \mathrm{MHz}$, and $3.2 \mathrm{dBi}$ at $960 \mathrm{MHz}$.

\section{Design of the RFID Reader Antenna}

The RFID reader antenna can be configured with two or more separated radiating elements for transmitting and receiving, and their separation distance is set to be large 


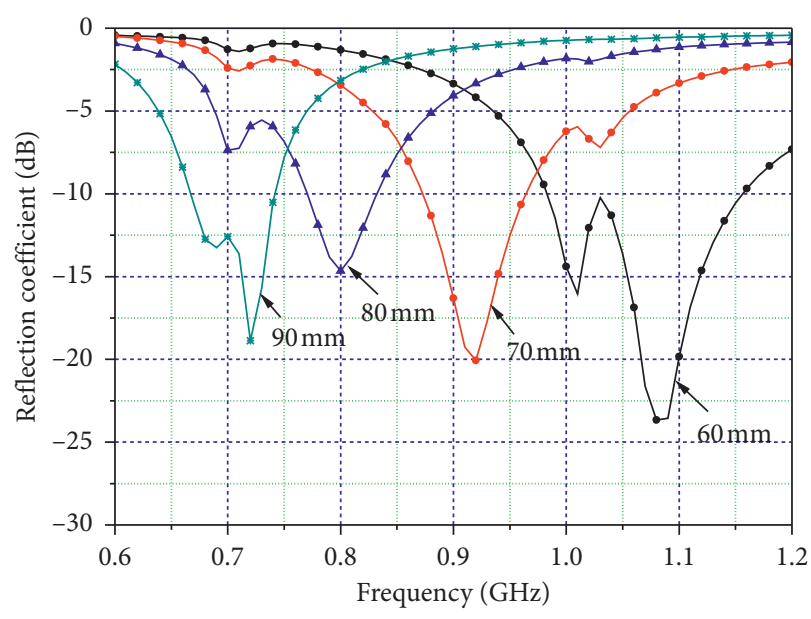

(a)

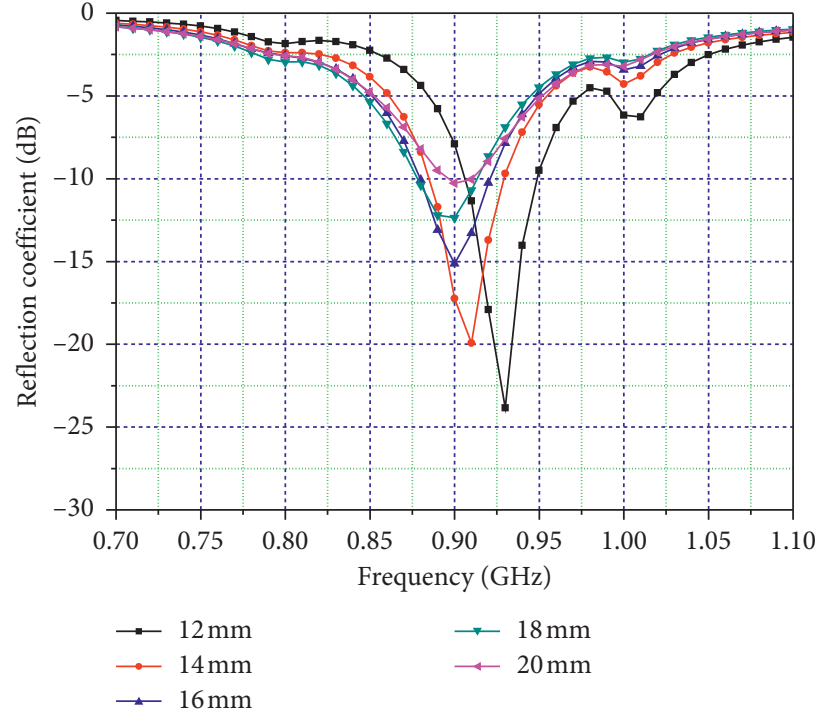

(b)

FiguRE 3: Effects of antenna geometry on reflection coefficient: (a) radiator length and (b) separation distances between a shorting line and a feed line.

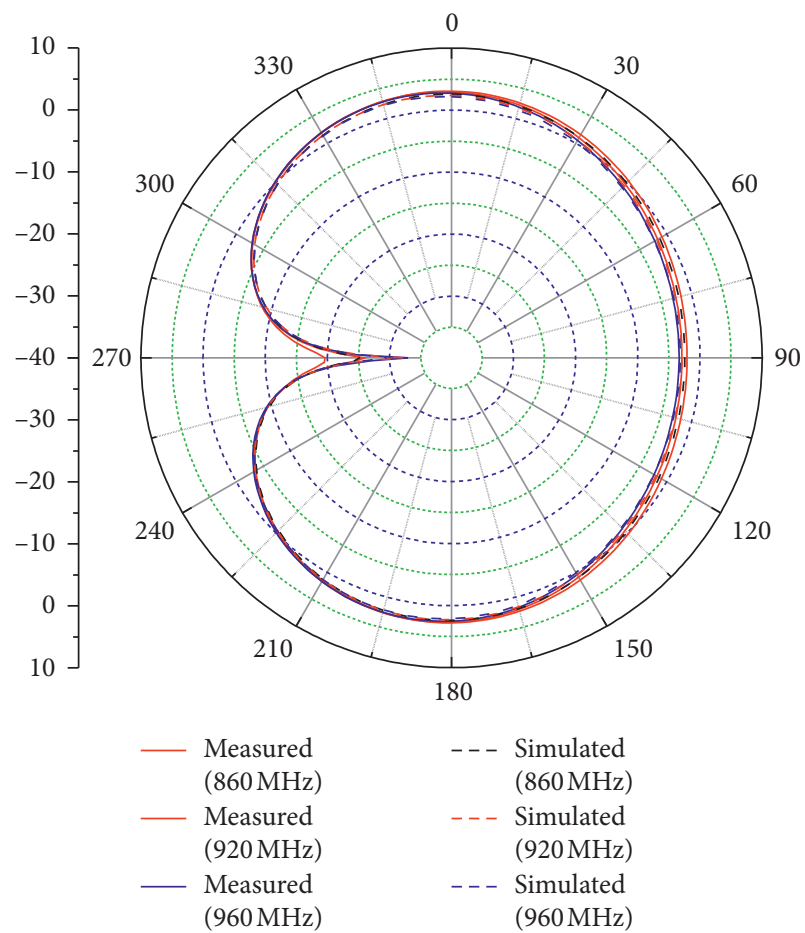

(a)

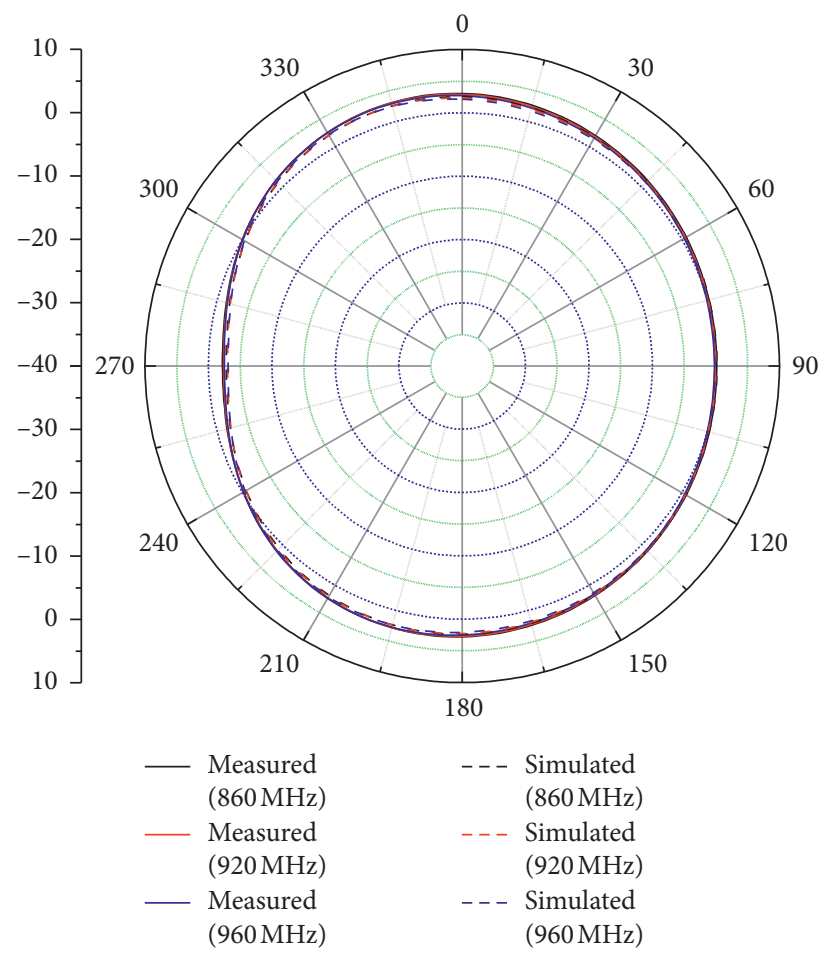

(b)

FIGURE 4: Measured and simulated radiation patterns: (a) yz-plane and (b) $x z$-plane.

enough to give the required $\mathrm{Tx}$ and $\mathrm{Rx}$ isolation. However, the overall antenna size depends upon the separation distance between radiating elements, and very much larger antenna size is needed to achieve higher Tx and Rx isolation. In addition, a circulator is used for a reader antenna between the transmitter and receiver for the cancellation of the transmit leakage wave. However, when the reader antenna is not matched to the circulator, the isolation between the transmitter and receiver is affected by the reflection coefficient of the reader antenna. 
Figure 5 shows the equivalent circuits with a Wilkinson power divider, which has two hybrid couplers. The scattering matrix for the ideal 3-dB hybrid coupler is as follows:

$$
\begin{gathered}
{\left[\begin{array}{l}
b_{1} \\
a_{p 1}^{\prime} \\
a_{p 4}^{\prime} \\
b_{4}
\end{array}\right]=\frac{-1}{\sqrt{2}}\left[\begin{array}{llll}
0 & j & 1 & 0 \\
j & 0 & 0 & 1 \\
1 & 0 & 0 & j \\
0 & 1 & j & 0
\end{array}\right]\left[\begin{array}{c}
a_{1} \\
b_{p 1}^{\prime} \\
b_{p 4}^{\prime} \\
a_{4}
\end{array}\right],} \\
{\left[\begin{array}{l}
b_{2} \\
b_{p 2} \\
b_{p 3} \\
b_{3}
\end{array}\right]=\frac{-1}{\sqrt{2}}\left[\begin{array}{llll}
0 & j & 1 & 0 \\
j & 0 & 0 & 1 \\
1 & 0 & 0 & j \\
0 & 1 & j & 0
\end{array}\right]\left[\begin{array}{c}
a_{2} \\
a_{p 2} \\
a_{p 3} \\
a_{3}
\end{array}\right] .}
\end{gathered}
$$

The scattering matrix of the ideal $90^{\circ}$ Wilkinson power divider is expressed as follows:

$$
\begin{gathered}
{\left[\begin{array}{l}
b_{p 1} \\
b_{5} \\
a_{p 2}
\end{array}\right]=-\frac{j}{\sqrt{2}}\left[\begin{array}{lll}
0 & 1 & 1 \\
1 & 0 & 0 \\
1 & 0 & 0
\end{array}\right]\left[\begin{array}{l}
a_{p 1} \\
a_{5} \\
b_{p 2}
\end{array}\right],} \\
{\left[\begin{array}{l}
b_{p 4} \\
b_{6} \\
a_{p 3}
\end{array}\right]=-\frac{j}{\sqrt{2}}\left[\begin{array}{lll}
0 & 1 & 1 \\
1 & 0 & 0 \\
1 & 0 & 0
\end{array}\right]\left[\begin{array}{l}
a_{p 4} \\
a_{6} \\
b_{p 3}
\end{array}\right] .}
\end{gathered}
$$

From equations (1)-(4), input and output equations are given as follows:

$$
\begin{gathered}
{\left[\begin{array}{l}
b_{1} \\
b_{4}
\end{array}\right]=\frac{-1}{\sqrt{2}}\left[\begin{array}{ll}
j & 1 \\
1 & j
\end{array}\right]\left[\begin{array}{l}
b_{p 1}^{\prime} \\
b_{p 4}^{\prime}
\end{array}\right],\left[\begin{array}{l}
a_{p 1}^{\prime} \\
b_{p 4}^{\prime}
\end{array}\right]=\frac{-1}{\sqrt{2}}\left[\begin{array}{ll}
j & 1 \\
1 & j
\end{array}\right]\left[\begin{array}{l}
a_{1} \\
a_{4}
\end{array}\right],} \\
{\left[\begin{array}{l}
b_{2} \\
b_{3}
\end{array}\right]=\frac{-1}{\sqrt{2}}\left[\begin{array}{ll}
j & 1 \\
1 & j
\end{array}\right]\left[\begin{array}{l}
a_{p 2} \\
a_{p 3}
\end{array}\right],\left[\begin{array}{l}
b_{p 2} \\
b_{p 3}
\end{array}\right]=\frac{-1}{\sqrt{2}}\left[\begin{array}{ll}
j & 1 \\
1 & j
\end{array}\right]\left[\begin{array}{l}
a_{2} \\
a_{3}
\end{array}\right] .}
\end{gathered}
$$

It can be substituted by the following equation:

$$
\begin{aligned}
& {\left[\begin{array}{l}
b_{p 1} \\
b_{p 4}
\end{array}\right]=\left[\begin{array}{l}
b_{p 2} \\
b_{p 3}
\end{array}\right],} \\
& {\left[\begin{array}{l}
a_{p 2} \\
a_{p 3}
\end{array}\right]=\left[\begin{array}{l}
a_{5} \\
a_{6}
\end{array}\right]=\left[\begin{array}{cc}
\Gamma_{a} & 0 \\
0 & \Gamma_{b}
\end{array}\right]\left[\begin{array}{l}
b_{5} \\
b_{6}
\end{array}\right],} \\
& {\left[\begin{array}{l}
b_{5} \\
b_{6}
\end{array}\right]=\left[\begin{array}{l}
a_{p 2} \\
a_{p 3}
\end{array}\right] .}
\end{aligned}
$$

Two transfer functions for input and output:

$$
\left[\begin{array}{l}
b_{1} \\
b_{4}
\end{array}\right]=\frac{-1}{\sqrt{2}}\left[\begin{array}{ll}
j & 1 \\
1 & j
\end{array}\right]\left[\begin{array}{c}
b_{p 1}^{\prime} \\
b_{p 4}^{\prime}
\end{array}\right],
$$$$
\left[\begin{array}{c}
b_{p 1}^{\prime} \\
b_{p 4}^{\prime}
\end{array}\right]=\left[\begin{array}{ll}
\beta_{a} & 0 \\
0 & \beta_{b}
\end{array}\right]\left[\begin{array}{l}
b_{p 1} \\
b_{p 4}
\end{array}\right],
$$$$
\left[\begin{array}{l}
b_{1} \\
b_{4}
\end{array}\right]=\frac{-1}{\sqrt{2}}\left[\begin{array}{ll}
j & 1 \\
1 & j
\end{array}\right]\left[\begin{array}{ll}
\beta_{a} & 0 \\
0 & \beta_{b}
\end{array}\right]\left[\begin{array}{l}
b_{p 1} \\
b_{p 4}
\end{array}\right]
$$$$
=\frac{-1}{\sqrt{2}}\left[\begin{array}{ll}
j & 1 \\
1 & j
\end{array}\right]\left[\begin{array}{ll}
\beta_{a} & 0 \\
0 & \beta_{b}
\end{array}\right]\left(\frac{-1}{\sqrt{2}}\right)\left[\begin{array}{ll}
j & 1 \\
1 & j
\end{array}\right]\left[\begin{array}{l}
a_{2} \\
a_{3}
\end{array}\right]
$$$$
=\frac{1}{2}\left[\begin{array}{cc}
-\left(\beta_{a}-\beta_{b}\right) & j\left(\beta_{a}+\beta_{b}\right) \\
j\left(\beta_{a}+\beta_{b}\right) & \left(\beta_{a}-\beta_{b}\right)
\end{array}\right]\left[\begin{array}{l}
a_{2} \\
a_{3}
\end{array}\right],
$$

$$
\left[\begin{array}{l}
b_{2} \\
b_{3}
\end{array}\right]=\frac{-1}{\sqrt{2}}\left[\begin{array}{ll}
j & 1 \\
1 & j
\end{array}\right]\left[\begin{array}{cc}
\Gamma_{a} & 0 \\
0 & \Gamma_{b}
\end{array}\right]\left[\begin{array}{l}
a_{p 1} \\
a_{p 4}
\end{array}\right],
$$

$$
\left[\begin{array}{l}
a_{p 1} \\
a_{p 4}
\end{array}\right]=\left[\begin{array}{ll}
\beta_{a} & 0 \\
0 & \beta_{b}
\end{array}\right]\left[\begin{array}{c}
a_{p 1}^{\prime} \\
a_{p 4}^{\prime}
\end{array}\right]
$$

$$
\begin{gathered}
{\left[\begin{array}{l}
b_{2} \\
b_{3}
\end{array}\right]=\frac{-1}{\sqrt{2}}\left[\begin{array}{ll}
j & 1 \\
1 & j
\end{array}\right]\left[\begin{array}{cc}
\Gamma_{a} & 0 \\
0 & \Gamma_{b}
\end{array}\right]\left[\begin{array}{ll}
\beta_{a} & 0 \\
0 & \beta_{b}
\end{array}\right]\left(\frac{-1}{\sqrt{2}}\right)\left[\begin{array}{ll}
j & 1 \\
1 & j
\end{array}\right]\left[\begin{array}{l}
a_{1} \\
a_{4}
\end{array}\right]} \\
=\frac{1}{2}\left[\begin{array}{l}
-\left(\beta_{a} \Gamma_{a}-\beta_{b} \Gamma_{b}\right) \\
\left.j\left(\beta_{a} \Gamma_{a}+\beta_{b} \Gamma_{b}\right)+\beta_{b} \Gamma_{b}\right)
\end{array}\right]\left[\begin{array}{l}
a_{1} \\
\\
a_{4}
\end{array}\right],
\end{gathered}
$$

where $\beta_{a}$ and $\beta_{b}$ are the amplitude and phase errors of the compensated circuits in paths. The four-port equations for a hybrid coupler with Wilkinson power divider have the following scattering matrix: 


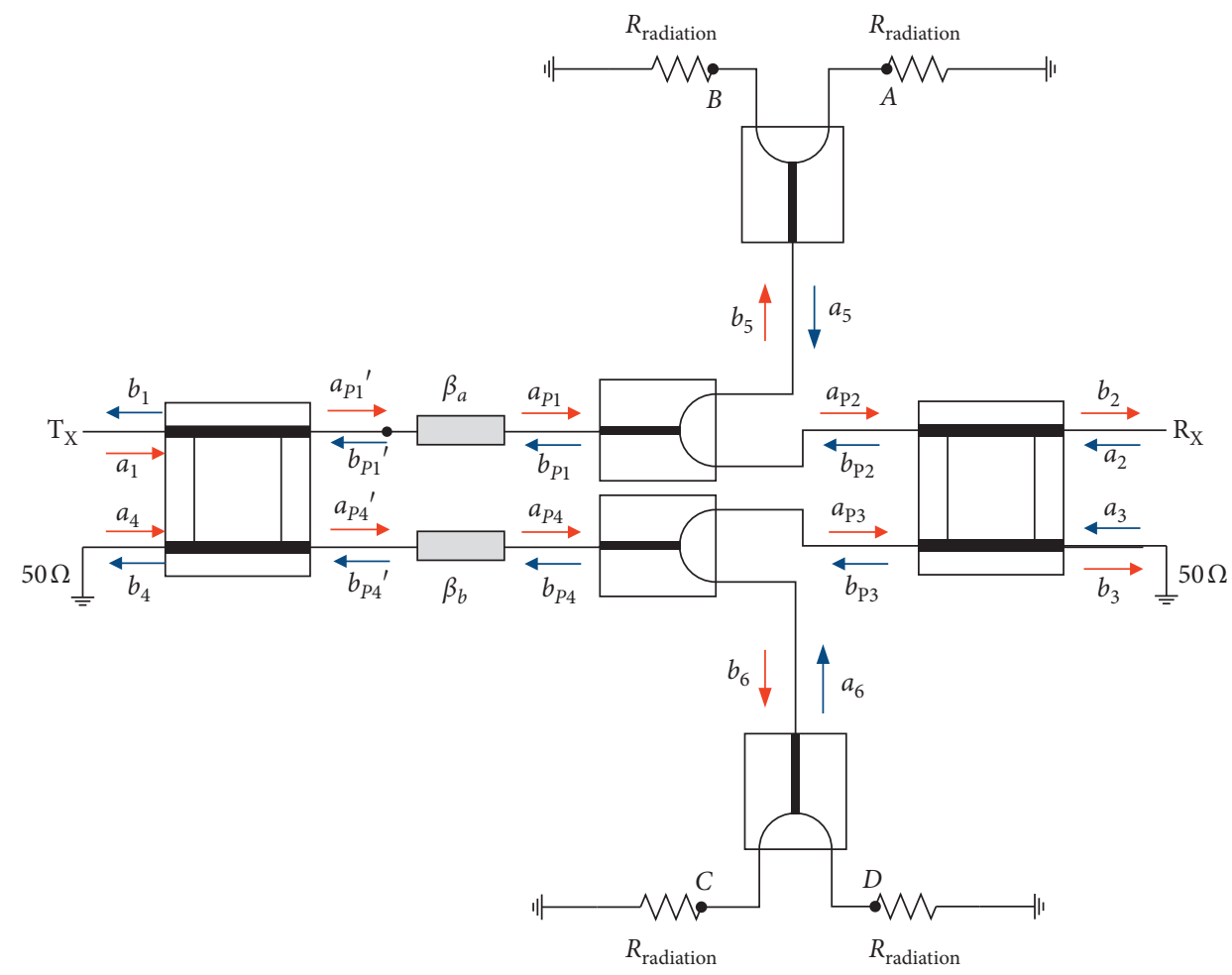

FIGURE 5: The equivalent circuits with a Wilkinson power divider.

$$
\begin{aligned}
& {\left[\begin{array}{l}
b_{1} \\
b_{2} \\
b_{3} \\
b_{4}
\end{array}\right]=\frac{1}{2}\left[\begin{array}{l}
-\left(\beta_{a} \Gamma\right. \\
j\left(\beta_{a} \Gamma\right.
\end{array}\right]} \\
& \frac{b_{2}}{a_{1}}=-\frac{1}{2}\left(\Gamma_{a}-\Gamma_{b}\right)=0
\end{aligned}
$$$$
\left.\begin{array}{cc}
j\left(\beta_{a}+\beta_{b}\right) & 0 \\
0 & j\left(\beta_{a} \Gamma_{a}+\beta_{b} \Gamma_{b}\right) \\
0 & \left(\beta_{a} \Gamma_{a}-\beta_{b} \Gamma_{b}\right) \\
\left(\beta_{a}-\beta_{b}\right) & 0
\end{array}\right]\left[\begin{array}{l}
a_{1} \\
a_{2} \\
a_{3} \\
a_{4}
\end{array}\right]
$$$$
\mathrm{RL}=-20 \log |C| \text {. }
$$

When the ideal case $\left(\beta_{a}=\beta_{b}=1\right)$,

The scattering matrix seen by the Tx and Rx ports can be expressed as follows:

$$
\left[\begin{array}{l}
a_{5} \\
a_{6}
\end{array}\right]=\left[\begin{array}{ll}
\Gamma_{a} & C \\
C & \Gamma_{b}
\end{array}\right]\left[\begin{array}{l}
b_{5} \\
b_{6}
\end{array}\right],
$$

where $a_{5}$ and $a_{6}$ represent the incident wave and reflected wave, $\Gamma_{a}$ and $\Gamma_{b}$ are reflection coefficients, and $C$ is the coupling coefficient.

We can derive the reflection coefficient at the antenna port as follows:

$$
\mathrm{RL}=-20 \log \left|\frac{b_{1}}{a_{1}}\right|=-20 \log \left|\frac{1}{2}\left(\Gamma_{b}-\Gamma_{a}\right)+j C\right| .
$$

As the proposed reader antenna has a rotationally symmetrical geometry, $\Gamma_{a}$ and $\Gamma_{b}$ are equal, and from (10),
The reflection coefficient $(\mathrm{RL})$ at the reader antenna port is the same as the isolation between ports $\mathrm{Tx}$ and $\mathrm{Rx}$, if the $90^{\circ}$ Wilkinson power divider is ideal.

This article presents a four-feed PIFA, two hybrid couplers, and four Wilkinson power dividers with wide beamwidths and bandwidths. The proposed antenna artificially reduced the gain of the antenna by using two hybrid couplers and four Wilkinson power dividers. We need low read distances for medical application as this will prevent the reading of unnecessary tags in the vicinity. The radiating patch is fed by the feed network with equal amplitude and the antenna consists of four PIFAs sequentially rotated and fed with phase angles of $0^{\circ}, 90^{\circ}, 180^{\circ}$, and $270^{\circ}$.

The geometry of the proposed reader antenna is shown in Figure 6. The antenna is composed of four printed PIFAs, two hybrid couplers, and four Wilkinson power dividers. The four printed PIFAs are sequentially rotated and fed with equal amplitudes, but with different phase angles $0^{\circ}, 90^{\circ}$, $180^{\circ}$, and $270^{\circ}$. The proposed reader antenna has dimensions of $150 \mathrm{~mm} \times 150 \mathrm{~mm}$, and the dielectric substrate of FR-4 (thickness: $1 \mathrm{~mm}, \varepsilon r: 4.4, \delta=0.025$ ) is used. Four print PIFA 


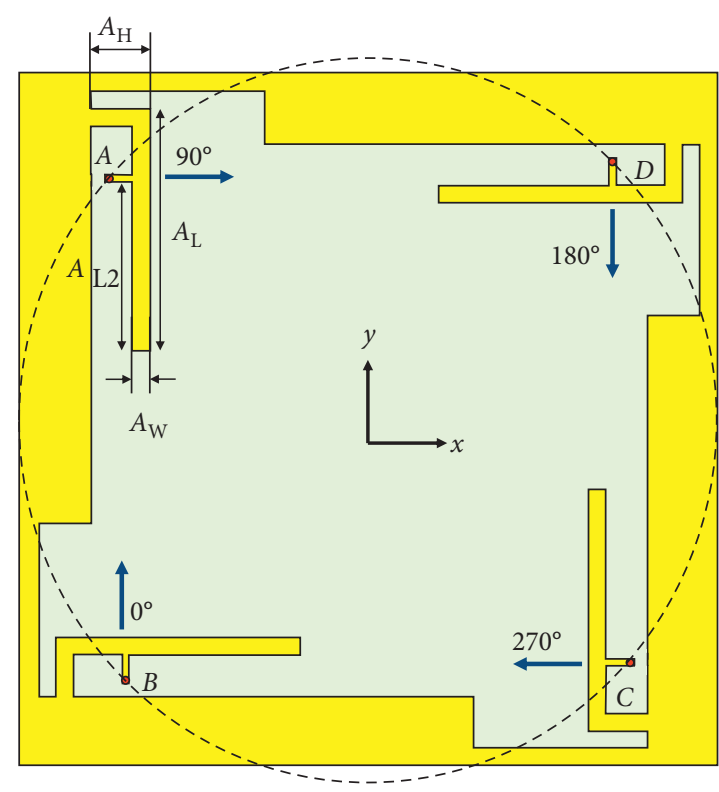

(a)

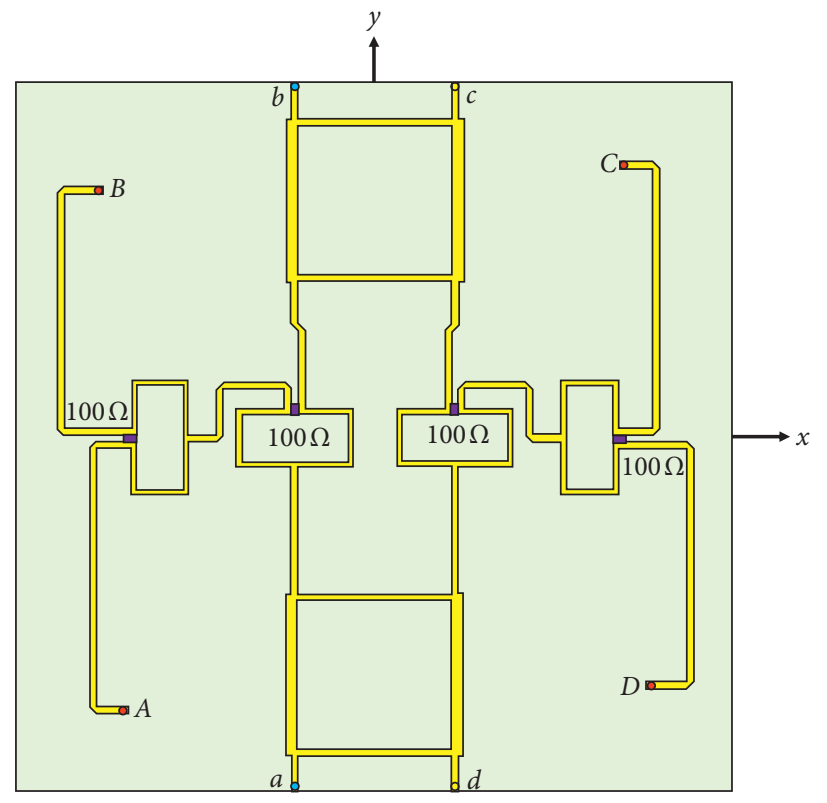

(b)

Figure 6: Geometry of the proposed reader antenna: (a) Top plane and (b) bottom plane.

feed points are directly connected to the bottom microstrip feed line network $(A, B, C$, and $D)$. The optimal parameters can be chosen as $A_{\mathrm{L}}=70 \mathrm{~mm}, A_{\mathrm{W}}=5 \mathrm{~mm}, A_{\mathrm{L} 2}=50 \mathrm{~mm}$, and $A_{\mathrm{H}}=17 \mathrm{~mm}$ based on the extensive simulation using Ansys HFSS. Figure 7 shows the simulated results for the feed point arrangements.

The printed PIFA was then removed and the antenna part was replaced by a metal ground. The simulations were performed using Ansys HFSS. Figure 7 shows that the value of $\min \left|S_{b a}\right|,\left|S_{c a}\right|$ is the smallest. Therefore, because $\left|S_{c a}\right|>\left|S_{b a}\right|$, port $b$ should be used as the Rx port corresponding to the Tx port $a$. Port $c$ and $d$ were terminated with $50 \Omega$. The simulation was performed in order to investigate the characteristics of the mutual coupling between the radiator point $(A, B, C$, and $D)$. In all cases, the obtained characteristic of $20 \mathrm{~dB}$ isolation is shown in Figure 7.

\section{Experiment Results of the Proposed Reader Antenna}

The proposed reader antenna design approach is verified by implementing a prototype antenna and measuring its performance. The simulation results have been obtained from commercial Ansys HFSS software to ensure that the obtained results are trustworthy. The reflection coefficient and isolation of the reader antenna were measured with an Agilent Vector Network Analyzer (85107B) in an anechoic chamber.

Figure 8(a) shows the measured input impedance on a Smith chart for the two feed port (Tx and Rx ports) of the reader antenna; they clearly have the same behavior over the frequency range. Figure 8(b) shows the measured reflection coefficient and interport coupling between the Tx ports. The antenna is operated from 780 to $1000 \mathrm{MHz}$ with a bandwidth

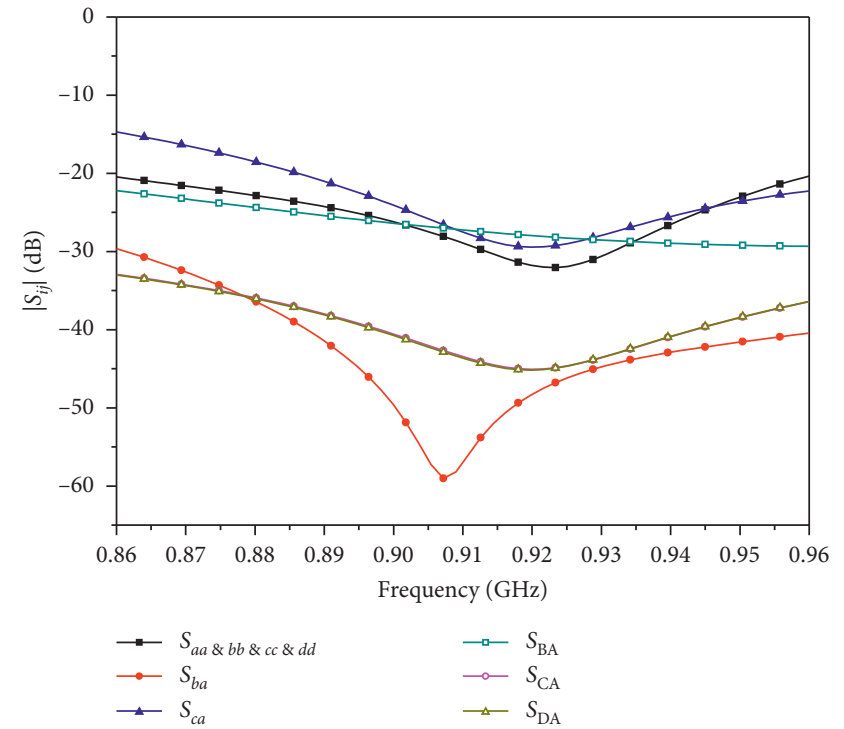

FIGURE 7: Simulated mutual coupling against frequency between feed point, and radiator point.

of $25 \%$. The impedance bandwidth obtained is wide enough to cover North American $(902-928 \mathrm{MHz})$, Korean (917-923.5 MHz), and Japanese $(916.7-923.5 \mathrm{MHz})$ applications. The measured interport coupling between the Tx and $\mathrm{Rx}$ ports of the proposed antenna is better than $40 \mathrm{~dB}$ over the frequency band.

Figure 9 shows the measured radiation patterns of the proposed reader antenna at resonant frequencies 902, 920, and $928 \mathrm{MHz}$ for the Tx port. Experimental results of the radiation patterns were obtained in an anechoic chamber at the Korea RFID/USN Center, Inchon, and the Republic of Korea. The antenna gains and radiation patterns were 


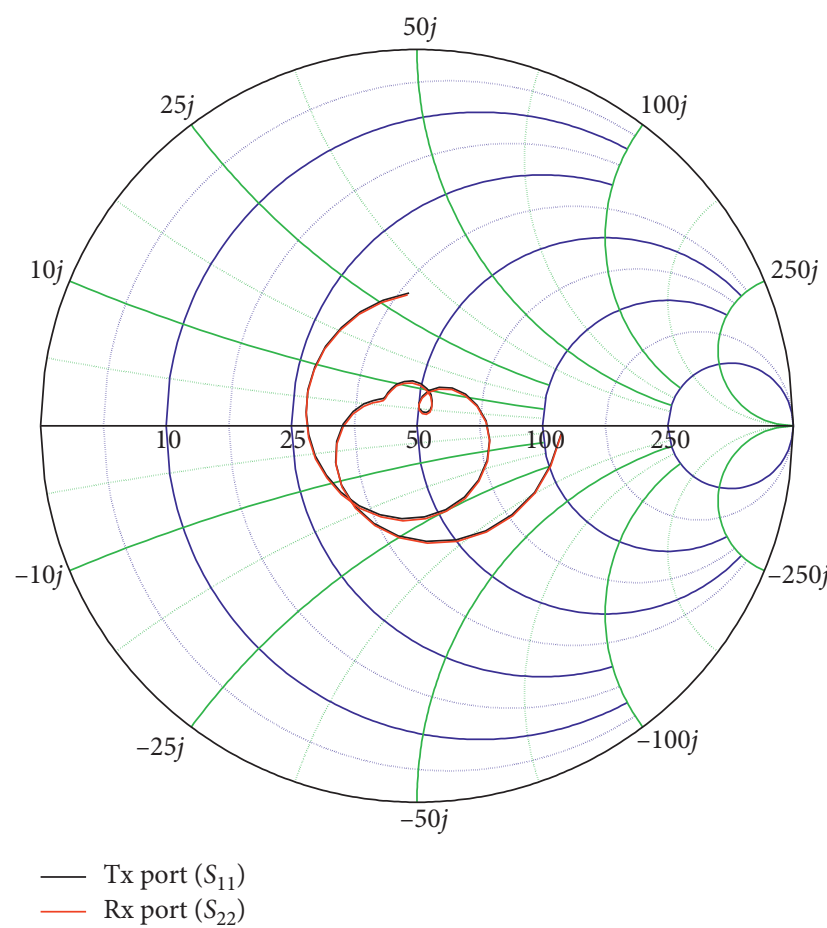

(a)

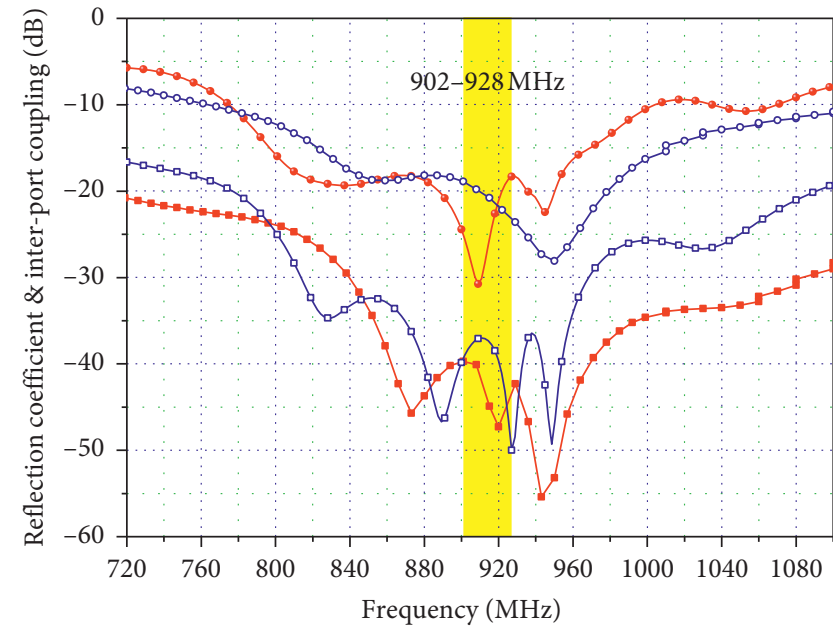

$\rightarrow$ Measured $\left(S_{11}\right)$

$\rightarrow$ Measured $\left(S_{21}\right)$

$\multimap$ Simulated $\left(S_{11}\right)$

$\longrightarrow$ Simulated $\left(S_{21}\right)$

FIGURE 8: Measured input impedance, reflection coefficient, and interport coupling of the proposed reader antenna: (a) input impedance on a Smith chart and (b) reflection coefficient and isolation.

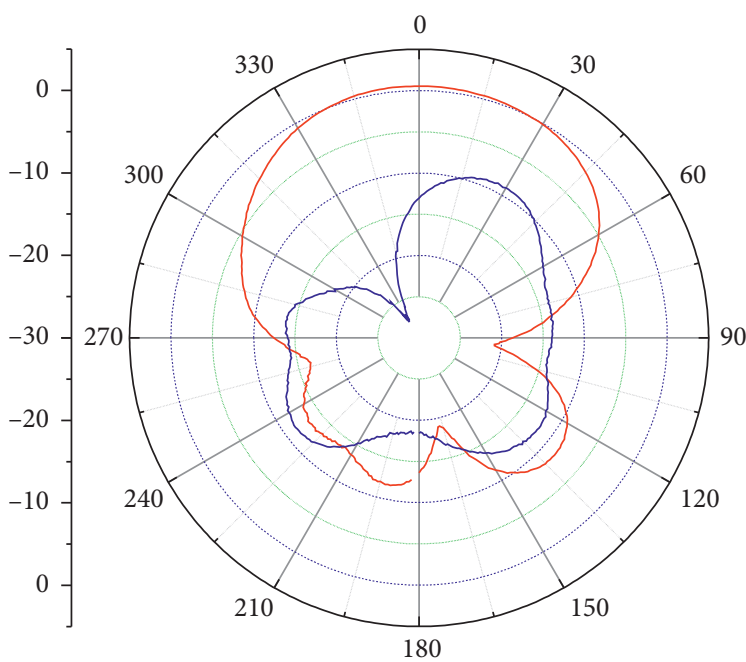

Co-pol (902 MHz)

- Cross-pol (902 MHz)

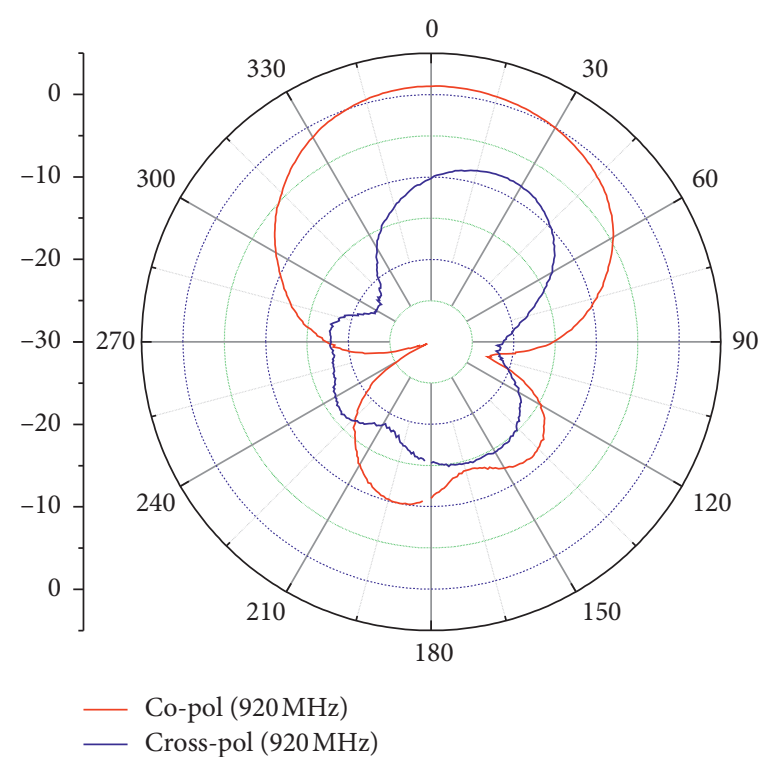

(b)

Figure 9: Continued. 


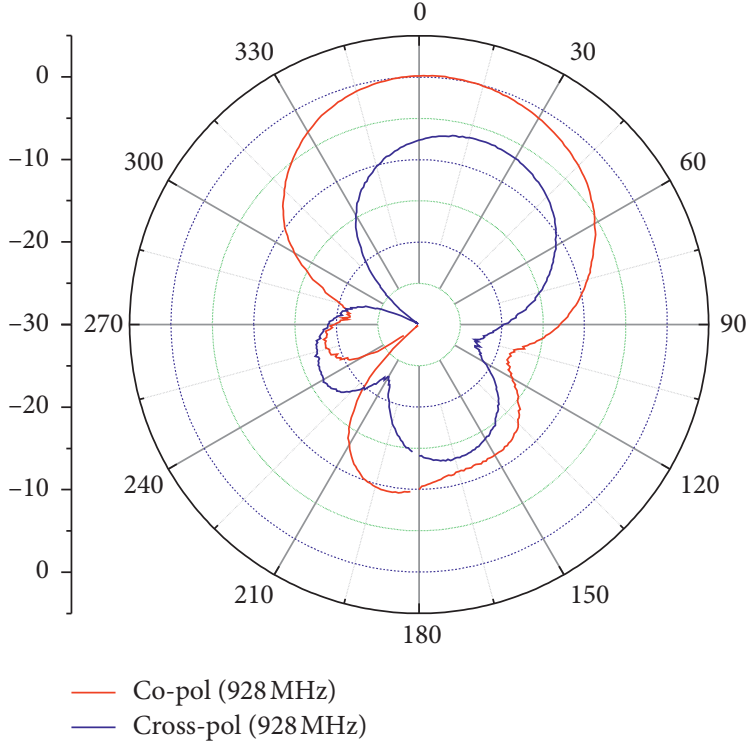

(c)

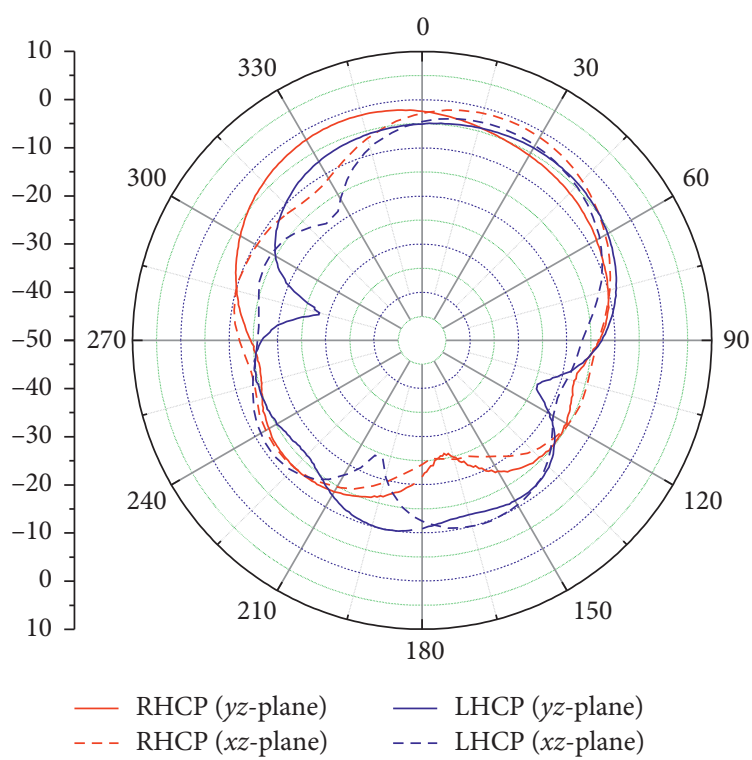

(e)

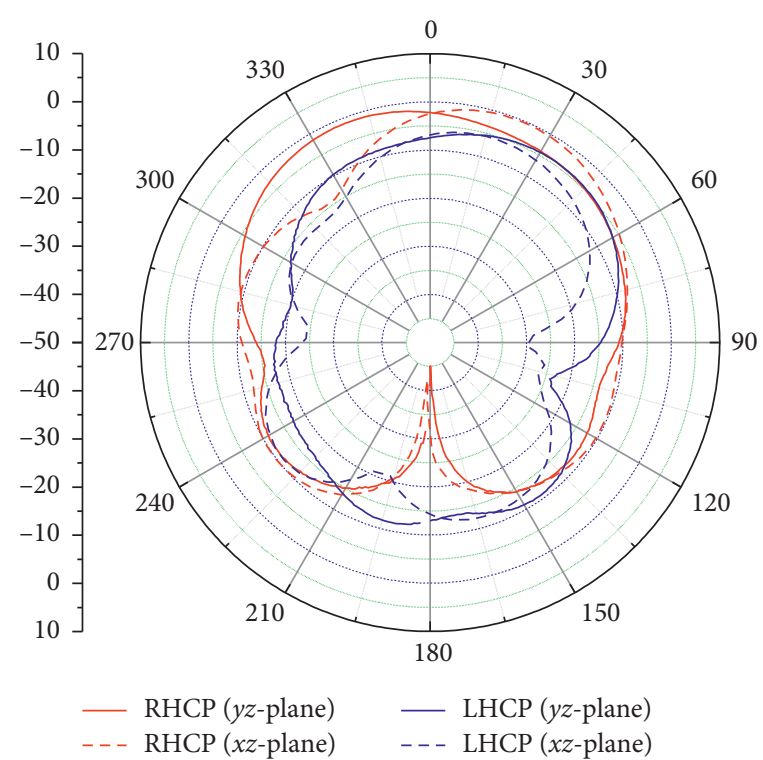

(d)

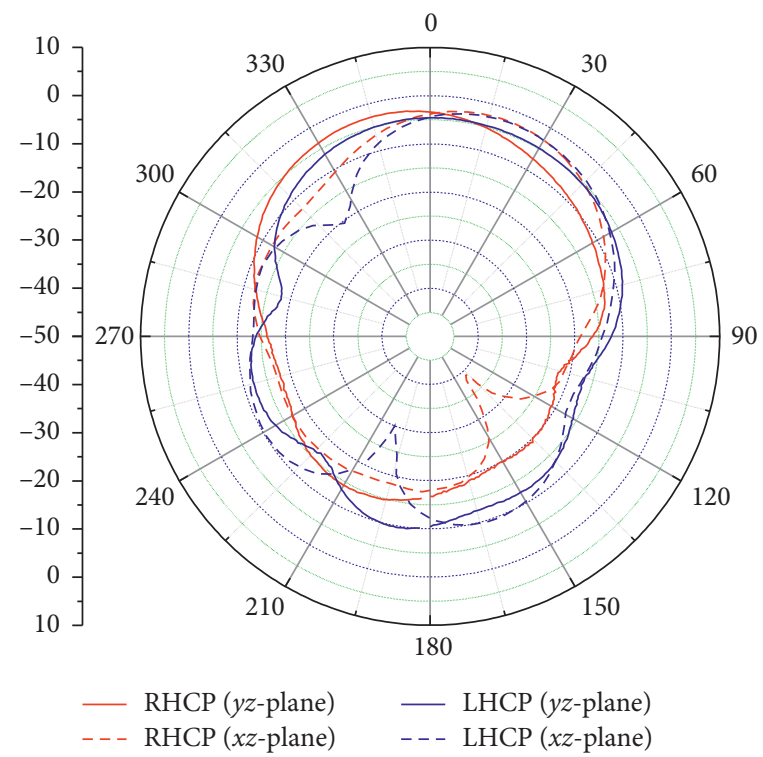

(f)

Figure 9: Measured radiation patterns: (a) $y z$-plane at $902 \mathrm{MHz}$, (b) $y z$-plane at $920 \mathrm{MHz}$, (c) $y z$-plane at $928 \mathrm{MHz}$, (d) R/LHCP at $902 \mathrm{MHz}$, (e) R/LHCP at $920 \mathrm{MHz}$, and (f) R/LHCP at $928 \mathrm{MHz}$.

measured in the middle range using an Agilent E5071C antenna measurement system. The antenna has stable radiation patterns and low back lobes across the entire bandwidth. The antenna has a symmetrical design, so the radiation patterns are almost symmetrical. The measured radiation performance is given in Table 1 .

\section{Experiment Results of Multitag Identification Rate for Medical Sample Tube}

We published a paper on an ultracompact UHF passive RFID tag antenna for medical sample tubes [25]. The multitag identification rate was compared using two types of reader antenna (far and near-field). We measured the reading range and multitag identification rate using the proposed reader antenna.

The tag antenna was described in [25] and the number of sample tubes is one hundred medical sample tubes. Figure 10 shows the setup environment of multitag identification rate. The medical sample tubes are measured using three types of reader antenna: near-field (MT-269508), far-field (ALA97C), and the proposed reader antenna. The reader antennas are positioned under the sample tube box at the separation distance, and tag identifications is performed. The multitag identification rate measurement is carried out in an anechoic chamber at the Korea RFID/USN Center, Inchon, the Republic of Korea. The input power of the reader is $1 \mathrm{~W}$ $(30 \mathrm{dBm})$. The medical sample tubes are measured at an 
TABLE 1: Measured radiation performance of the reader antenna.

\begin{tabular}{|c|c|c|c|c|c|c|c|c|}
\hline \multirow{2}{*}{\multicolumn{2}{|c|}{$\begin{array}{c}\text { Frequency } \\
(\mathrm{MHz})\end{array}$}} & \multirow{4}{*}{$\begin{array}{c}\text { Gain (dBic) } \\
\text { Bore sight } \\
0.6 \\
0.53\end{array}$} & \multirow{4}{*}{$\begin{array}{c}\text { AR }(\mathrm{dB}) \\
\text { Bore sight } \\
0.82 \\
0.8\end{array}$} & \multicolumn{2}{|c|}{ HPBW (deg) } & \multicolumn{2}{|c|}{$\mathrm{F} / \mathrm{B}$ ratio $(\mathrm{dB})$} & \multirow{3}{*}{$\begin{array}{c}\text { Efficiency (\%) } \\
38\end{array}$} \\
\hline & & & & \multirow{3}{*}{$\begin{array}{c}y z \text {-plan } \\
90^{\circ} \\
94^{\circ}\end{array}$} & \multirow{2}{*}{$\frac{x z \text {-plan }}{68^{\circ}}$} & \multirow{2}{*}{$\frac{y z \text {-plan }}{11.8}$} & \multirow{2}{*}{$\frac{x z \text {-plan }}{12}$} & \\
\hline 002 & Sim. & & & & & & & \\
\hline 902 & Mea. & & & & $70.81^{\circ}$ & 12 & 12.67 & 30.3 \\
\hline \multirow{2}{*}{920} & Sim. & 1.92 & 1.02 & $72^{\circ}$ & $65^{\circ}$ & 10.08 & 11.23 & 52 \\
\hline & Mea. & 1.03 & 1 & $80^{\circ}$ & $70.51^{\circ}$ & 11 & 11.97 & 46.9 \\
\hline \multirow{2}{*}{928} & Sim. & 1.2 & 0.88 & $70^{\circ}$ & $66.5^{\circ}$ & 9 & 10.72 & 41 \\
\hline & Mea. & 0.98 & 0.8 & $75^{\circ}$ & $70.09^{\circ}$ & 9.6 & 10.98 & 39.43 \\
\hline
\end{tabular}

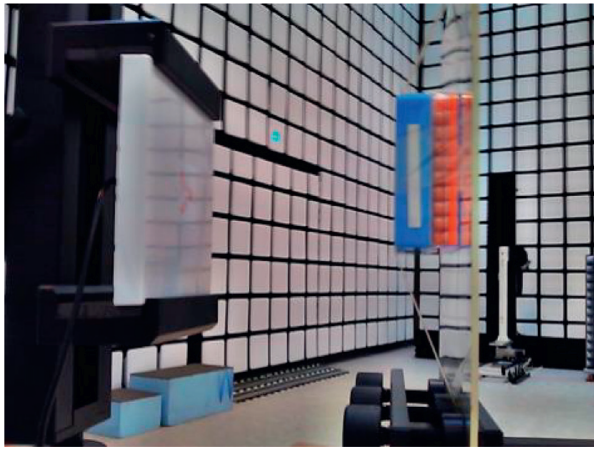

(a)

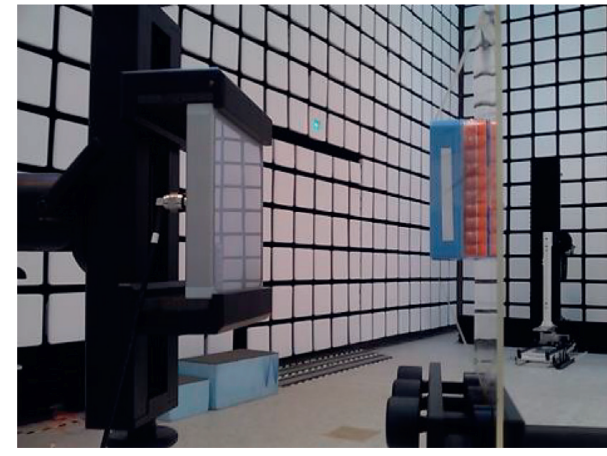

(b)

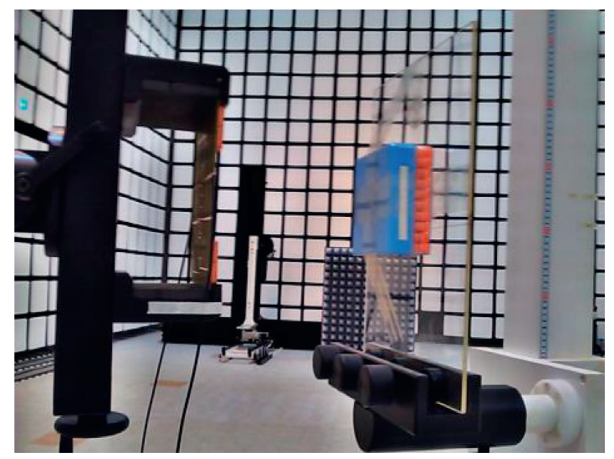

(c)

Figure 10: Setup environment of multitag identification rate: (a) alien far-field reader antenna, (b) MTG near-field reader antenna, and (c) proposed reader antenna.

interval of four seconds, and the reader antenna automatically moves from $10 \mathrm{~mm}$ to $100 \mathrm{~mm}$.

Figure 11 shows the measured reading range and multitag identification rate for three cases. From the figure, the near-field reader antenna is identified to have a maximum of 95 sample tubes at $10 \mathrm{~mm}$, the far-field reader antenna is identified to have a maximum of 88 sample tubes at $20 \mathrm{~mm}$, and the proposed reader antenna is identified to have a maximum of 100 sample tubes at $10 \mathrm{~mm}$. The proposed reader antenna is perfectly identified at $10 \mathrm{~mm}$. We need low read distances for medical application as it will prevent reading unnecessary tags in the vicinity, and, hence, the proposed reader antenna performs better than a regular high-gain antenna. Table 2 is a comparison with references $[6,7]$. Both antennas are near-field reader antennas. As shown in the table, it can be confirmed that the multitag identification rate and the number of the proposed reader antenna is excellent.

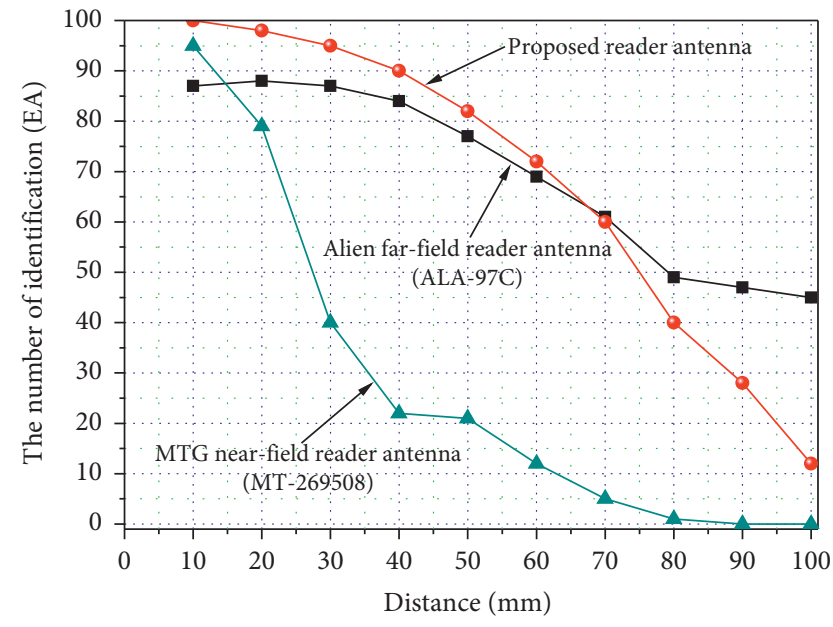

FIgURE 11: The number of tag identification. 
TABLE 2: Tag identification rate comparison.

\begin{tabular}{lccc}
\hline & Proposed & Ref [6] & Ref [7] \\
\hline Frequency $(\mathrm{MHz})$ & $780-1000$ & $910-940$ & $814-1050$ \\
Gain $\left(f_{\mathrm{c}}=920 \mathrm{MHz}\right)$ & $1.03 \mathrm{dBic}$ & $6.8 \mathrm{dBi}$ & - \\
Size $(\mathrm{mm})$ & $150 \times 150 \times 1$ & $300 \times 300 \times 100$ & $170 \times 170 \times 1$ \\
Reader type & Far-field & Naer-field & Naer-field \\
Number of tags $(\mathrm{EA})$ & 100 & 100 & 25 \\
Tag identification $(\%)$ & 100 & 80 & 100 \\
\hline
\end{tabular}

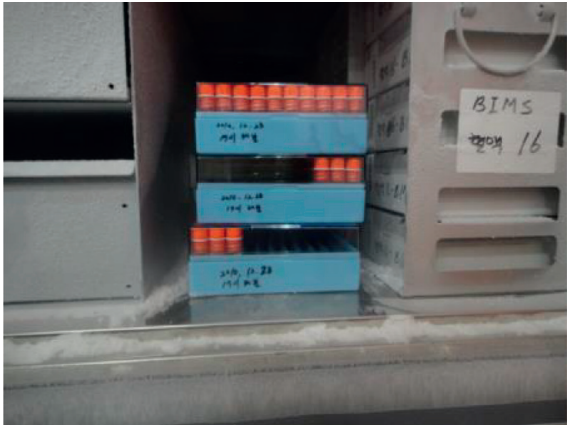

(a)

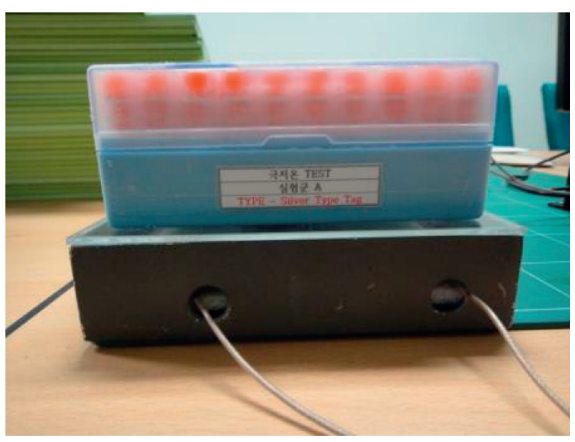

(c)

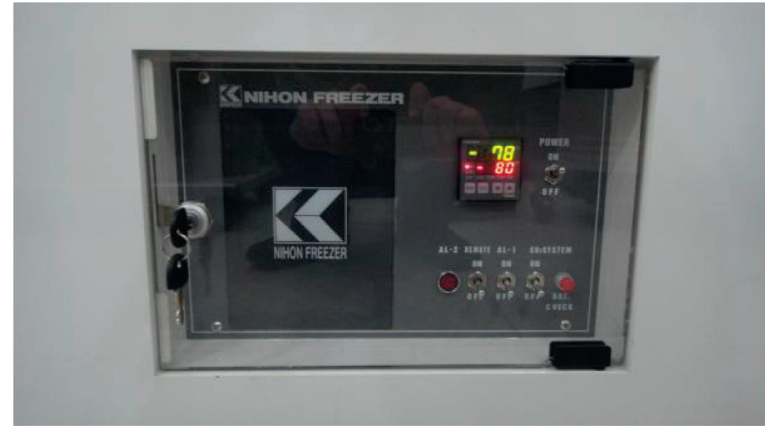

(b)

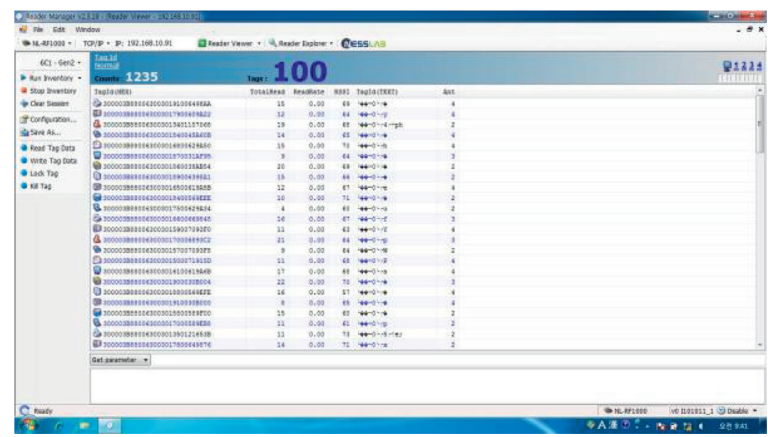

(d)

Figure 12: Setup environment of an extremely low temperature experiment: (a) sample tube boxes placed in a freezer, (b) setup temperature, (c) measurement setup, and (d) measured results.

Freeze preservation is required to prevent the degradation of blood and human tissue samples. The RFID system used presently in the smart cold chain operates at $-40^{\circ} \mathrm{C}$, but no system currently available can operate at $-80^{\circ} \mathrm{C}$. The realtime use of an RFID system at extremely low temperatures is very difficult because of the serious electric wave distortion due to humidity and frost. We performed measurements on medical sample tubes filled with a normal saline solution at an extremely low temperature $\left(-80^{\circ} \mathrm{C}\right)$. These extremely low temperature experiments were performed at the Chungnam National University Hospital, Daejeon, the Republic of Korea. We measured the identification rate at 3-week intervals for 10 sample tube boxes placed in a freezer. Figure 12 shows the setup of an extremely low temperature experiment.

The measurements obtained at an extremely low temperature are given in Table 3. As shown in Table 3, the proposed reader antenna completely identified all samples in extremely low temperature condition for all periods.
TABle 3: Measurement performance at an extremely low temperature.

\begin{tabular}{lcccccccccc}
\hline \multirow{2}{*}{ Week (W) } & \multicolumn{10}{c}{ Tube box samples } \\
& 1 & 2 & 3 & 4 & 5 & 6 & 7 & 8 & 9 & 10 \\
\hline 1 & 100 & 100 & 100 & 100 & 100 & 100 & 100 & 100 & 100 & 100 \\
3 & 100 & 100 & 100 & 100 & 100 & 100 & 100 & 100 & 100 & 100 \\
6 & 100 & 100 & 100 & 100 & 100 & 100 & 100 & 100 & 100 & 100 \\
9 & 100 & 100 & 100 & 100 & 100 & 100 & 100 & 100 & 100 & 100 \\
\hline
\end{tabular}

\section{Conclusion}

In this paper, we present the design of a UHF RFID reader antenna that uses the far-field region. We improved the isolation between antennas by using two hybrid couplers and four power dividers. The proposed reader antenna was designed, fabricated, and tested for UHF RFID applications. The proposed reader antenna covers a range of $860 \mathrm{MHz}$ to 
$960 \mathrm{MHz}$ and its $\mathrm{Tx} / \mathrm{Rx}$ isolation is $40 \mathrm{~dB}$. A comparison of the multitag identification rate of the far-field reader antenna and a near-filed reader antenna shows that the proposed reader antenna has an excellent isolation feature and multitag identification rate. Measurement results also showed that the proposed reader antenna could completely identify all samples even at extremely low temperature conditions.

\section{Data Availability}

The simulation and experimental data used to support the findings of this study are included within the article.

\section{Conflicts of Interest}

The authors declare that there are no conflicts of interest regarding the publication of this paper.

\section{Acknowledgments}

This research was supported by the Ministry of Science and ICT, Republic of Korea, under the R\&D program of ETRI.

\section{References}

[1] K. Finkenzeller, RFID Handbook, Wiley, New York, NY, USA, 2nd edition, 2003.

[2] S. A. Bokhari, J.-F. Zurcher, J. R. Mosig, and F. E. Gardiol, "Near fields of microstrip antennas," IEEE Transactions on Antennas and Propagation, vol. 43, no. 2, pp. 188-197, 1995.

[3] R. J. Paknys, "The near field of a wire grid model," IEEE Transactions on Antennas and Propagation, vol. 39, no. 7, pp. 994-999, 1991.

[4] X. Qing, Z. N. Chen, and C. K. Goh, "UHF near-field RFID reader antenna with capacitive couplers," Electronics Letters, vol. 46, no. 24, pp. 1591-1592, 2010.

[5] J. Shi, X. Qing, and Z. N. Chen, "Electrically large zero-phaseshift line grid-array UHF near-field RFID reader antenna," IEEE Transactions on Antennas and Propagation, vol. 62, no. 4, pp. 2201-2208, 2014.

[6] C. H. Cho, C. Y. Lee, J. K. Ryoo, and H. S. Choo, "Planar nearfield RFID reader antenna for item-level tagging," IEEE Antennas and Wireless Propagation Letters, vol. 10, pp. 1100-1103, 2011.

[7] X.-D. Wei, H.-L. Zhang, and B.-J. Hu, "Novel broadband center-fed UHF near-field RFID reader antenna," IEEE Antennas and Wireless Propagation Letters, vol. 14, pp. 703-706, 2014.

[8] H.-S. Jang, W.-G. Lim, and J.-W. Yu, "UHF RFID reader front-end having wideband and stable $\mathrm{Tx} / \mathrm{Rx}$ isolation characteristic," Microwave and Optical Technology Letters, vol. 52, no. 11, pp. 2467-2473, 2010.

[9] W. G. Lim, S. Y. Park, W. I. Son, M. Q. Lee, and J. W. Yu, "RFID reader front-end having robust Tx leakage canceller for load variation," IEEE Transactions on Microwave Theory and Techniques, vol. 57, no. 5, pp. 1348-1355, 2009.

[10] H.-W. Son, H. Park, K.-H. Lee, G.-J. Jin, and M.-K. Oh, "UHF RFID reader antenna with a wide beamwidth and high return loss," IEEE Transactions on Antennas and Propagation, vol. 60, no. 10, pp. 4928-4932, 2012.
[11] W. G. Lim and J. W. Yu, "Balanced circulator structure with enhanced isolation characteristics," Microwave and Optical Technology Letters, vol. 50, no. 9, pp. 2389-2391, 2008.

[12] H. Lee and T. Itoh, "Isolation circuits based on metamaterial transmission lines for multiplexers (invited paper)," Journal of Electromagnetic Engineering and Science, vol. 13, no. 3, pp. 141-150, 2013.

[13] J.-N. Lee and J.-H. Jung, "Design of the planar cross dipole reader antenna for UHF RFID systems," Journal of Electromagnetic Waves and Applications, vol. 26, no. 7, pp. 962-972, 2012.

[14] W. G. Lim, W. I. Son, K. S. Oh, and W.-K. Kim, "Compact integrated antenna with circulator for UHF RFID system," IEEE Antennas and Wireless Propagation Letters, vol. 7, pp. 673-675, 2008.

[15] H.-W. Son, H. Park, and H.-G. Jeon, "Design of a circularly polarised radio-frequency identification reader antenna with high return loss," IET Microwaves, Antennas \& Propagation, vol. 5, no. 15, pp. 1844-1848, 2011.

[16] P. Wang, G. Wen, J. Li, Y. Huang, L. Yang, and Q. Zhang, "Wideband circularly polarized UHF RFID reader antenna with high gain and wide axial ratio beamwidths," Progress In Electromagnetics Research, vol. 129, pp. 365-385, 2012.

[17] Y.-F. Lin, C.-H. Lee, S.-C. Pan, and H.-M. Chen, "Proximityfed circularly polarized slotted patch antenna for RFID handheld reader," IEEE Transactions on Antennas and Propagation, vol. 61, no. 10, pp. 5283-5286, 2013.

[18] I.-J. Hyeon, T. J. Jung, S. J. Lim, and C.-W. Baek, "Packageplatformed linear/circular polarization reconfigurable antenna using an integrated silicon RF MEMS switch," ETRI Journal, vol. 33, no. 5, pp. 802-805, 2011.

[19] J. Ju, D. Kim, W. Lee, and J. Choi, "Design method of a circularly-polarized antenna using fabry-pérot cavity structure," ETRI Journal, vol. 33, no. 2, pp. 163-168, 2011.

[20] J.-H. Lu and S.-F. Wang, "Planar broadband circularly polarized antenna with square slot for UHF RFID reader," IEEE Transactions on Antennas and Propagation, vol. 61, no. 1, pp. $45-53,2013$.

[21] W.-S. Lee, S. T. Khang, W.-S. Lee, and J.-W. Yu, "Hemispheric coverage multi-beam switched antenna array using a 4-port feeding network for UHF RFID dead zone avoidance," in Proceedings of the 2013 Asia-Pacific Microwave Conference, pp. 254-257, Seoul, South Korea, 2013.

[22] Z.-M. Liu and R. R. Hillegass, "A 3 patch near field antenna for conveyor bottom read in RFID sortation application," in Proceedings of the IEEE Antennas and Propagation Society International Symposium 2006, pp. 1043-1046, Albuquerque, NM, USA, 2006.

[23] H.-W. Son, J.-N. Lee, and G.-Y. Choi, "Design of compact RFID reader antenna with high transmit/receive isolation," Microwave and Optical Technology Letters, vol. 48, no. 12, pp. 2478-2481, 2006.

[24] Ansys, High frequency structure simulator (HFSS), Ver. 10, 2005.

[25] J.-N. Lee, "Design of an ultra-compact UHF passive RFID tag antenna for a medical sample tube," ETRI Journal, vol. 34, no. 6, pp. 974-977, 2012. 